"This is the peer reviewed version of Rachel Cooper "How might I have been?" which is forthcoming in Metaphilosophy. This article may be used for non-commercial purposes in accordance with Wiley Terms and Conditions for Self-Archiving."

\title{
How Might I Have Been?
}

\section{Rachel Cooper}

\begin{abstract}
What would my life have been like if I had been born more intelligent? Or taller? Or a member of the opposite sex? Or a non-biological being? Plausibly some of these questions make sense while others stretch the limits of sense-making. In addressing questions of how I might have been genetic essentialism is popular, but I argue that genetic essentialism, and other versions of origin essentialism for organisms, must be rejected. I then consider the prospects for counterpart theory, and show how counterpart theory can be used to illuminate volitional accounts of identity as proposed by Harry Frankfurt. This enables one to make sense of claims that, say, being gay, or Deaf, or Black, can be essential to someone's identity. The discussion is then extended to show how it can be made applicable to the transworld identity theorist who denies that individuals possess necessary properties.
\end{abstract}


Consider the following two scenarios: First we discover that ugliness in later life can be prevented by taking vitamin $\mathrm{Z}$ early in pregnancy. Given that being ugly is a disadvantage, those of us who were born ugly prior to the discovery feel a certain amount of regret. If only scientists had discovered the power of vitamin $\mathrm{Z}$ earlier, we think, we could have been better looking.

In the second scenario, scientists discover that it is possible to turn human embryos into white rhinos via genetic intervention. Given that rhinos are rare, while humans are common, the benefits of this procedure for boosting rhino numbers are clear. An expectant mother starts to wonder whether she should volunteer for the procedure. She asks whether her baby would have a better life as a rhino, and, she gets stuck. Some of her problems are due to a lack of empirical data; she's not sure whether rhinos generally have good lives. But many of the problems run deeper. Does the procedure for turning human embryos into rhino embryos result in an individual who might have been human being a rhino? Or, does it destroy an individual who would otherwise have become a human being and use its genes as mere raw material for constructing a completely new entity?

Working out when it makes sense to say that I might have been other than I am matters because this sets limits to the possibilities that I can sensibly regret or blame others for. For example, people with Huntington's disease have a limited life expectancy. But unless it is true that people with Huntington's might have not had this genetic condition, it makes no sense for them to regret that no intervention was used to make them healthy, nor to blame their parents for neglecting to utilise such "therapies". Similarly, modal truths place limits on what a 
person might reasonably plan to become. For example, if, as a white woman, there is no possible future in which I am Black then there's no sense in me trying to become Black.

Deciding how I might have been requires a general metaphysical account. There are two main options: one may either believe in transworld identities or adopt counterpart theory. ${ }^{1}$ Those who believe in transworld identities think that the individuals that exist in the actual world also exist in other possible worlds and have different properties in some of them. ${ }^{2}$ Those who embrace counterpart theory follow David Lewis (1979) and claim that actually existing individuals are world-bound - that is individuals who exist in the actual world exist only in the actual world. In other possible worlds there are individuals very like those in the actual world. The possible people who are very like me in some respect are my counterparts and can be used as a comparison class to make sense of claims about how I might have been different. Thus, while those who believe in transworld identities will say that what makes it true that I might have had ginger hair is that there are possible worlds where I have ginger hair, the counterpart theorist will say that the truth-maker of the claim is that there are possible worlds that contain counterparts of me who possess ginger hair.

1 Alternatively one can embrace a hybrid approach whereby one believes in transworld identity for some types of entity, and counterparts for other types of entity, an option developed by Forbes (1985), who thinks that transworld identity theory should be adopted for organisms but counterpart theory for artefacts.

2 Of historical interest only, there have also been some who have claimed that individuals have all the properties that they actually possess in all possible worlds. This view is commonly attributed to Leibniz (Mackie, 2006a, p.22). 
As Penelope Mackie has convincingly argued (2006a, 2006b), those who believe in transworld identities must respond to 'Chisholm's paradox' (1967), and must consider whether there are possible worlds in which two actual individuals, say Noah and Adam, swap all their properties. The transworld identity theorist has two options. The first option is to argue that there are limits to the properties that actually existing individuals can lose because individuals possess necessary properties, such that the individual cannot possibly exist without possessing the necessary property. ${ }^{3}$ The second option is to accept that there are indeed possible worlds in which Noah and Adam have swapped all their properties, and that this world differs from the actual world only in that the "bare identities" of the individuals with Noah-ish and Adam-ish properties are different. The alternative to these options is to reject talk of transworld identities, and adopt counterpart theory.

Running parallel to these metaphysical debates, within moral philosophy there has been much discussion of volitional and narrative accounts of identity. Most writers have thought that the debates about identity in moral philosophy should be kept separate from discussions in metaphysics and that at least two distinct senses of identity are in play. For example, Appiah (1990) distinguishes between "metaphysical” and "ethical” identity, while De Grazia (2005 p.264) would have us treat "numerical" versus "narrative" identity separately. One of my aims in this paper is to show that this is mistake and that one can draw fruitful links between the

3 This will be a start. To prevent swapping between all possible pairs individuals will need to have essential properties that are both necessary and sufficient for their identity in all possible worlds. Having some necessary properties will prevent only some potential property swaps, because it is not enough to prevent swapping between pairs of individuals both of which possess the same necessary property, eg if Noah is necessarily human and so is Adam then this is compatible with them property-swappping. 
debates in metaphysics and moral philosophy. I will do this via considering how links can be made between the volitional account of identity developed by Harry Frankfurt and the metaphysical debates. Debates about identity in moral and political philosophy of course go much beyond the work of Frankfurt, ${ }^{4}$ but in drawing links between his work and the metaphysical disputes I will at least begin making progress in showing how the debates in moral philosophy and metaphysics can help inform each other. Drawing such links is particularly important because of the prominence of arguments regarding identity that arise in identity politics, where individuals often claim that characteristics such as being a woman, or being Black, or being Deaf, can be essential to identity.

Of the metaphysical positions, the most popular option in discussions about how people might have been is some version of genetic essentialism (which itself is a version of origin essentialism). As such, I will start by considering the viability of this approach. I will argue that genetic essentialism, and other versions of origin essentialism for organisms, must be rejected. I then briefly consider what other properties, apart from those connected to origin, might be necessary for an individual's identity across possible worlds and argue that there are no plausible candidates that will do much to constrain the ways that an individual might have been. The second section of the paper considers the prospects for counterpart theory. I will argue that this option is better than claiming that an individual's origin is necessary, and will show how counterpart theory can be used to illuminate volitional accounts of identity as proposed by Harry Frankfurt. I then extend the discussion and explore how the transworld

4 For example, though there is not space in this paper, it would be interesting to also consider also communitarian accounts of identity as developed by, for example, Taylor (1989), Sandel (1982). 
identity theorist who does not believe in individual essences but who instead believes in bare identities can address questions of how I might have been.

\section{Necessary properties for individuals}

Genetic essentialism has become the default position in much of philosophy (for example in debates about "wrongful life" in applied ethics (see Parfit 1984 ch.16, and, for discussion, Zohar 1991, Kahn 1991), and in arguments in the philosophy of biology about whether natural selection can explain the properties of individuals or only of populations (Sober 1995; Pust, 2004, p.771)). Genetic essentialists differ in their exact claims but all trace them back to Saul Kripke's arguments regarding the necessity of origins.

\subsection{The basis of genetic essentialism - the doctrine of the necessity of origins}

Kripke's Naming and Necessity $(1972,1980)$ is in some respects a difficult book. As a direct transcript of Kripke's verbally given lectures, arguments tend to be gestured at rather than made entirely explicit. In Naming and Necessity, Kripke suggests that our commonplace intuitions are in accordance with the doctrine of the necessity of origins. Kripke asks whether the Queen could have come from different parents. He concludes that she could not. 
How could a person originating from different parents, from a totally different sperm and egg, be this very woman?...It seems to me that anything coming from a different origin would not be this object. (1980, p.113)

Similar reasoning leads to the conclusion that his table could not have originated in any other block of wood (1980, pp.113-114); the doctrine of the necessity of origins is taken to apply to humans and artefacts equally. Not everyone shares Kripke's basic intuition that something about the origins of an entity must be necessary. Some think it possible that actual objects and people could have been created ex nihilo by God (e.g. Lowe, 1998, p.152; Oderberg, 2007, p.175). In the main text, Kripke relies on the idea that the necessity of origins accords with our intuitions, and offers nothing to convince those whose intuitions differ from his own.

However, in footnote 56, Kripke also claims that in a large class of cases the necessity of origins is susceptible of "something like a proof". The "proof" of footnote 56 has been subject to much discussion; Forbes (1985, pp.138-45) and Salmon (1981) construct versions of the proof, Robertson (1998) demonstrates problems with them. Attempts to reconstruct a proof, and criticisms of attempted proofs are currently ongoing. ${ }^{5}$ In the absence of a satisfactory proof, adherents of the doctrine of the necessity of origins adopt the position because they find it intuitively plausible. Here I shall show that here are various ways in which the doctrine of the necessity of origins might be explicated. I show that whichever option is taken leads to difficulties. To keep things simple, I will here consider chiefly the doctrine of the necessity of origins as it might apply to human beings. Human beings are a case that is of central interest

\footnotetext{
${ }^{5}$ See, for example, Hawthorne and Gendler 2000, Robertson 2000, Rohrbaugh and de Rosset
} 2004, Robertson and Forbes 2006, Damnjanovic 2010 
to us. If no version of the doctrine of the necessity of origins can be made to work for human beings then the doctrine loses much of its interest.

\subsection{Possible versions of the doctrine.}

Possible versions of the doctrine of the necessity of origins hold that it is necessary for human beings to have:

1. their actual parents.

2. to originate in exactly the physical matter that they actually originate in.

3. to have the exact genetic make-up that they actually have.

Or alternatively we might consider weaker versions:

$2 b$. to originate in roughly the physical matter that they actually originate in.

3b. to have roughly the genetic make-up that they have.

Each option will be considered in turn.

\subsubsection{Is it necessary for humans to have their actual parents?}

The idea that it may be necessary for a person to have the 'parents' that they actually have comes directly from Kripke. I shall argue that talk of 'parents' is so vague as to be useless, and that on elaboration the intuition that 'parents' are necessary must collapse into the view that something else about origins is necessary (either the original physical matter or genetic make-up). The problem is that "parents" can be hard to pin down. Sperm, eggs and embryos 
can be donated and implanted in others. Some embryos may be clones, and DNA can be spliced and recombined in complex ways. Kripke held that such "recherché possibilities" could be ignored (1980, p.112), but this is no longer a viable option. Reproductive technologies have made unqualified talk of "parents" obsolete. For Kripke's purposes, the most plausible clarification is to say that the parents are the people who supply the genetic material. Intuitively it seems that I could have been implanted in a surrogate mother, or adopted at birth, and yet still have been the same person. If we decide that the identity of the genetic material is what matters, we are still left with two options. We might claim that the actual physical matter that makes up the genes is important, or we might think of genes in a more abstract sense, as information carriers, and think that the important question is whether the capacity of the genes to carry information remains the same. Below, in sections 1.2 .2 . and 1.2.3. each will be considered in turn, and some prima facie concerns raised. Then in section 1.3 the conclusive argument against such approaches will be discussed - neither can deal with the Problem of Tolerance

\subsubsection{Is it necessary for humans to originate in the physical matter that they actually originate in?}

Kripke claims that it is necessary for a table to be made from the actual hunk of wood that it is made from. Should he make an analogous claim about human beings? Is it necessary for humans to originate in the physical particles that actually originally constituted them?

The problem of recycling means that being made of certain physical particles can be at most necessary, but not also sufficient, for the identity of a human being (McKay, 1986, p.297). 
The particles that make me up existed long before my birth, and will continue to exist long after my death. It is possible that at some point in the future, those same particles will come together in some other sperm and egg and make up another person. Although having their origins in the same physical materials, this person will not be me. Thus sameness of matter could only be necessary, but not also sufficient, for identity.

Furthermore, the idea that the actual matter that makes me up is necessary to my identity has highly counter-intuitive consequences. Sperms and eggs are made from fundamental particles, and in the case of human beings, most of the fundamental particles that make us up come from the food that we eat. Thus, if my father had eaten a different burger from the burger that he actually ate, the particles that made up the sperm that partially made me would have been different. If we interpret the doctrine of the necessity of origins as claiming that humans have to be made from the actual physical particles that make them up we are forced to hold the counterintuitive claim that menu choices determine the identity of one's children. The basic problem here is that fundamental particles intuitively seem interchangeable. Given that all protons are qualitatively the same, if some of my protons are swapped with others what difference does this make?

\subsubsection{Is it necessary for a human to have the genes (considered as blueprints) that they} actually have?

What about thinking of genes as sets of instructions - as abstract objects? Such a view has its attractions. It implies, as seems right, that if part of my genetic code was replaced by a 
physically different but functionally identical part, then this would not make any difference to my identity.

However, thinking of genes as "blueprints" may be wrongheaded. Over the last few decades the importance of environmental influences on development has come to be emphasised, especially by advocates of Developmental Systems Theory (Griffiths and Gray 1994). Developmental Systems Theory holds that "the role of the genes is no more unique that the role of many other factors" (1994, p.277). Development can be shaped by the environment pre-birth (the food the mother eats, the bacteria she harbours etc.) and the environment postbirth as much as it is shaped by genes. On such a view thinking of the genes as supplying the “instructions" for development makes no sense.

Furthermore, it is clear that some parts of our genetic code are more important than others. It is controversial whether our junk DNA is really junk, or whether it serves some purpose. Still it is likely that some of our genetic make-up has no phenotypic effects. If we think of our genes as being important for our identity in so far as our genes affect our phenotype then we would presumably conclude that junk DNA does not matter. Once we go down this line problems emerge. If we ask why we are tempted to discount changes to junk DNA, the answer can only be that it makes no phenotypic difference. But, now it looks like the reason we think that standard DNA is of importance is parasitic on the importance we attach to the phenotypic traits we see it as coding. And, if it is the phenotypic effects that we are ultimately interested in, it looks like we could forget about the genetic make-up of an embryo, and say directly that what matters for transworld identity is phenotypic similarity. But this is an option that no-one wishes to endorse, as we also have a strong intuition that organisms might have come to be 
born looking rather differently from the way they actually looked (if, for example, they came to be exposed to alcohol, or radiation, in utero).

\subsection{The Problem of Tolerance}

I have discussed prima facie problems with claiming that either the actual physical matter, or the genes considered as blueprints, are necessary for identity. The genetic essentialist might be able to get round these worries, and develop an account of the importance of genes that avoids conceiving of genes as merely abstract instructions. Still, however the view that genetic makeup is necessary is developed, I suggest that it will be unable to accommodate the Problem of Tolerance. The difficulty is that we should plausibly be tolerant of slight changes in origins. It is tempting to think that very small changes to origins - a different atom, or a different DNA allele - shouldn't matter. However as soon as we allow for some tolerance we run into difficulties when we consider what happens across possible worlds. As we move from world to world, making some changes to my genetic make-up as we go, small changes gradually add up to big changes. Cooper in possible world B may be genetically very similar to Cooper in possible world $\mathrm{A}$, and Cooper in world $\mathrm{C}$ is similar to Cooper in $\mathrm{B}$, and yet the Cooper in worlds $\mathrm{A}$ and $\mathrm{C}$ are unalike. If we tolerate small changes we will want to say that the Coopers in worlds A and B are identical, and that the Coopers in worlds B and C are identical. However, given that identity is a transitive relation, we cannot say this without also claiming that the Coopers in worlds $\mathrm{A}$ and $\mathrm{C}$ are identical - and this is not something we want to admit. 
Stalnaker considers the analogous case for artefacts, and the options that we have for resolving the problem.

...consider a sequence of possible worlds, each containing a bicycle that differs slightly in its composition from the bicycle in the preceding world, but such that the bicycle in the first world in the sequence has no parts in common with the bicycle in the last world. Identity, of course, is transitive. One cannot say that each bicycle is identical to the bicycles in the neighbouring worlds, but not to the corresponding bicycles in distant worlds. The argument suggests that one must either adopt an extreme form of mereological essentialism, requiring identity of all parts for identity of the whole, or else give up the standard account of identity across possible worlds. (Stalnaker, 1986, p.125)

There are two ways in which one might give up on the "standard account of identity across possible worlds". The first option is to claim that the accessibility relations between possible worlds are non-transitive: although possible world B is accessible from A, and possible world $\mathrm{C}$ is accessible from $\mathrm{B}$, possible world $\mathrm{C}$ need not be accessible from $\mathrm{A}$. This is a radical option, and though it has some advocates (Salmon, 1986), many think it is too high a price to pay (Coburn, 1986, pp.172-4). The other way to give up on the "standard account of identity across possible worlds" is to abandon all talk of transworld identity and to embrace counterpart theory instead. This is the option that will be explored in Section 2 of this paper. A third option, not considered by Stalnaker, is that one might construe his problem as a standard sorites paradox and deal with it via whatever method one employs in dealing with 
other sorites cases. To take this option, however, one needs to think that there is some solution to sorites cases. In any event, tolerance leads to a variety of other paradoxes of transworld identity that cannot be seen as sorites cases (Mackie, 2006, pp.59-64).

At the end of this section I hope to have demonstrated that essentialism for organisms is not a tenable position. There are, of course, varieties of individual essentialism other than origin essentialism. Some believe that an individual's immaterial soul is essential. For those who don't believe in souls, the problem is that apart from some property connected to the origins of an individual there appear to be no viable candidates for individual essences. While a property such as an individual's spatial location at some particular time would be suitably unique, it doesn't intuitively seem "important enough" to be essential.

Not all essentialists believe in individual essences. The sortal essentialist claims that although there are no individual essences there are kind essences, such that it is not possible for an individual to belong to a different kind than it actually belongs to (e.g. Wiggins 2001). Sortal essentialists can be surprisingly reticent in stating exactly what sortals they are committed to, but if biological species are taken to be sortals, then on such a position there is no possible world in which a human is a slug. If higher-level sortals, e.g. organism versus artefact, are considered fundamental, then at least there is no possible world in which a human being is a slab of concrete. As propounded by Wiggins, sortal essentialism is developed within a neoAristotelian framework. The basic idea is that there are natural kinds, such that members of a natural kind have different natural life cycles, and these life cycles inform principles of identity and differentiation for members of a kind. A tadpole, for example, is the sort of creature that develops into a frog. For this reason we take the tadpole and the frog to be the 
same individual. In contrast, it is not natural for a human to transform into a fly, and we would thus be likely to consider any human-to-fly process to have destroyed the human.

It is worth noting that the sorts of question about counterfactual possibilities for individuals that are of greatest practical import are precisely those where an Aristotelian sortal essentialism can be of least assistance. Questions about how I might have been are of most practical interest where they concern questions about whether a human might have been a different type of human (e.g. without genetic disease, of a different race, or sex), but the idea that there are different natural kinds of human being is implausible. In particular, the notion that races, or sexes possess essential properties is empirically unlikely (on race see Glasgow 2003, on sex see Dupré 1993 ch.3). Interesting practical questions also arise when we consider the counterfactual possibilities for organisms that are shaped by genetic technologies - but here again Aristotelian talk of natural life-cycles will be of little help, as these organisms precisely don't have natural life cycles. In any case, sortal essentialism cannot respond to Chisholm's Noah-Adam paradox, and here I will not consider it further.

In this section I have argued that origin essentialism should be eliminated as an option for thinking about counterfactual possibilities for individuals. This leaves us with no reason for thinking that individuals possess necessary properties that will stop them swapping properties with other individuals in other possible worlds. In responding to Chisholm's Noah-Adam paradox, we are thus left to choose between adopting counterpart theory or believing in "bare 
identities". Either option will be repulsive to many. ${ }^{6}$ Here I will not adjudicate between the approaches, but will rather consider first what one should say about counterfactual possibilities for individuals if one is a counterpart theorist, and second what one should say if one believes in bare identities. In considering counterpart theory I will also show how links can be made with the volitional account of identity developed by Harry Frankfurt. This discussion will then be extended to make it applicable to the believer in bare identities.

\section{Counterpart Theory}

Counterpart theorists claim that individuals are worldbound. That is, we who exist in the actual world exist in no other possible worlds. Thus, for the counterpart theorist, strictly speaking, talk of transworld identity makes no sense.

According to counterpart theorists, when I make a counterfactual claim, say, that I might have been born with blond hair, this means that there are possible worlds that contain my blondhaired counterparts. My counterparts are not identical with me - they are not mes in other possible worlds. Rather, my counterparts are possible individuals who are more or less like me and act as a comparison class for making sense of counterfactual statements.

\footnotetext{
6 The literature on counterpart theory is vast, but for some criticism of counterpart theory see Mackie 2006 ch.5; Merricks 2003, Fara \& Williamson 2005. For concerns about bare identities see Forbes 1985, pp127-8.
} 
How do we identify our counterparts? My counterpart in another possible world is the person most similar to me in important respects. ${ }^{7}$ As it is a similarity relation rather than an identity relation, the counterpart relation is not transitive (Lewis 1979, p113). My counterparts must be similar to me - but the extent and aspect in which they must be similar differs with context (Lewis, 1979, p.128). Depending on the context, we might take our counterparts to be those possible people who have origins that are most like ours, or who look most like us, or whatever. Counterpart theorists are happy to employ their theory to make sense of a weak form of essentialism. Lewis tells us that "an essential attribute of something is an attribute it shares with all of its counterparts" (Lewis 1979, p.120). However, one should note that given that we choose which attributes we consider important for determining someone's counterparts, we also, indirectly choose which attributes we will consider essential. For example, suppose that within some context I privilege genetic similarity. Then I will only consider possible people who are genetically identical to me to be my counterparts, and I will conclude that my genotype is essential to me. In another context, the results might be different. Suppose I instead focus on phenotypic similarity, then I will count some possible people who look like me but are genetically different as my counterparts, and in that context my genotype would not appear essential. If, as Lewis suggests, all of my counterparts are human, and thus I am essentially human, this is only because there is no context in which I am prepared to count a non-human as similar enough to me to be my counterpart. For the counterpart theorist, who counts as my counterparts, and which of my attributes are essential, depends on the context in which I am speaking and the choices that I make.

7 Sometimes two possible people in another possible world may be equally similar to me and both be my counterparts. (Lewis 1979, p113). One advantage of talking in terms of counterparts instead of in terms of transworld identity is that one can make sense of statements like "I might have been a twin" 


\subsection{Counterparts and volitional accounts of identity}

Running parallel to metaphysical debates, moral philosophers have proposed "volitional" and "narrative" accounts of identity. Few links have been drawn between the two literatures, but I will suggest that useful interconnections can be drawn.

\subsubsection{Frankfurt's volitional account of identity}

Harry Frankfurt has offered the best developed account of how one's volitional structure might be important for identity. Frankfurt views humans as having many and varied desires, some of which they endorse and some of which they do not (Frankfurt, 1971). You may be addicted to nicotine, for example, but experience your desires for nicotine as being alien. You fight against them. These desires are external to you, according to Frankfurt, and they don't count towards making you who you are. You will typically also have desires that you do endorse. For example, you may want to look after your children, or to travel the world. These cares do count towards making you who you are. Although Frankfurt presents his account somewhat differently in different writings, the basic idea remains the same - second order volitions, or "cares", are what matters for personal identity.

According to Frankfurt our cares constrain the possible courses of action that are available to us. 
A person may care so much...that he is subject to a kind of necessity. Because of this necessity, various courses of action that he would otherwise be able to pursue are effectively unavailable to him. It is impossible for him to pursue them...The reason is that he cannot bring himself to do so... (Frankfurt, 1999, p.111)

One might have various worries about Frankfurt's account (for criticism see, for example, Shoemaker 2003, Velleman 2002). Here I do not embrace a blanket version of Frankfurt's position. Rather I will argue that we can use counterpart theory to see how it is that a version of Frankfurt's account is convincing in some contexts.

\subsubsection{Frankfurt and counterparts}

On counterpart theory, one's counterparts vary with context. Depending on the specific issue, one compares one's actual self with a reference class of counterparts, who are similar to oneself in relevant ways, in order to determine how one might be different. One of the main contexts in which we consider counterfactual situations is when we are planning what to do. When we plan, we consider what the outcomes of various possible courses of action will be, and select the course of action that appears most likely to have good results.

In planning, we generally place certain constraints on the possibilities that we consider. In particular, in any context, the things that we care most about preserving are normally held 
constant. Let us compare two people, Loving Luke and Ambitious Alan. The most important thing in Loving Luke's life is his girlfriend. The most important thing to Ambitious Alan's is his career. Apart from their deepest cares, Luke and Alan live identical lives. They both currently have nice jobs, and nice houses, and nice partners. Both are faced with a decision, their girlfriends will be moving away for a couple of years to nurse a sick parent. Alan and Luke must decide whether to leave their jobs and move with their partners or to stay behind. When Loving Luke makes plans he does the following: he keeps his relationship with his girlfriend constant, and considers possible worlds in which the other elements of his life are different in order to seek out the best course of action. He thinks to himself, "I could get another job" or "Maybe I don't need to work for a couple of years". However, worlds in which he abandons his girlfriend are not amongst the worlds he considers. For Luke, splitting up with his girlfriend does not feature as a possible option. Ambitious Alan's thinking is different. He keeps his career constant, and considers only the possibilities that are compatible with career success. He considers worlds in which he sees his girlfriend at weekends, or splits with her and either gets another girlfriend, or is single. For each person, the possible worlds that they consider when planning are limited to those that are compatible with what they love most.

I must concede that our cares do not always constrain our planning. Sometimes we do not know our cares prior to acting, but rather, via acting and then feeling an emotional response, come too late to discover what we care about. A classic example is the teenager who deserts their boyfriend, or girlfriend, and then, through feeling upset at the split, discovers only too late that they were in love. I accept that such cases occur, and indeed that they are common enough that they are better considered to be indicative of the usual frailty and stupidity of 
human beings rather than being in any way pathological. This being said, I hold that there are enough cases where we do know our cares and use them to constrain our plans for the relationship between cares, plans and action that I have outlined above to be both usual and normative.

We can make sense of such planning in terms of counterpart theory. When we plan we normally consider only those possible worlds that are compatible with valuing the things we care about most. Thus, when we think about what we could do, the relevant counterparts are those that live in this set of possible worlds. In these worlds, Loving Luke has no counterpart who splits with his girlfriend. Frankfurt talks of "volitional necessities" - choices that we are compelled to make if we are to stay true to what we care about the most. Following his lead, we might also talk of the volitionally possible - where something is volitionally possible if it occurs in a possible world that is consistent with a person's deepest cares. It is not volitionally possible for Luke to abandon his girlfriend. While the terminology here may be new, the basic idea is not. Consider the phrase "X couldn't hurt a fly". It's never the case that a human is logically incapable of harming a fly, and seldom if ever the case that they are physically incapable of doing so. Rather, the phrase turns on the idea that some people are so opposed to violence that they would not be able to bring themselves to destroy a living creature. The basic idea - that a "would not" can be considered as a variety of "could not" is the same as that captured by talk of volitional necessities and possibilities.

Frankfurt himself does not talk in terms of possible worlds or counterparts, but my version of his account fits well with his own claims. Frankfurt compares volitional necessity with logical necessity. He says that in a way analogous to the way in which we cannot conceive of a 
logical contradiction "There are certain things that people cannot do, despite possessing the relevant natural capacities or skills, because they cannot muster the will to do them" (2004, p.46). He goes on to tell us that, "The necessities of a person's will guide and limit his agency. They determine what he may be willing to do, what he cannot help doing, and what he cannot bring himself to do" (2004, p.50).

While Frankfurt talks of one's cares as being essential to one's identity, counterpart theorists do not think that talk of transworld identity strictly makes sense. Still, Lewis allows that "we might say, speaking casually, that your counterparts are you in other worlds, that they and you are the same" (1979, p.112). Furthermore, as discussed previously, when speaking loosely, for the counterpart theorist, an essential attribute of something is an attribute it shares with all of its counterparts. Thus, loosely speaking, the counterpart theorist will allow us to say that in certain contexts one's counterparts are those possible people that share our cares, and in this context, one's cares are essential to one's identity. Admittedly, in other contexts, we will choose to pick out counterparts differently, and the attributes that will be considered essential for our identity will correspondingly shift. However, it is worth emphasising that the context in which we take our cares to pick out our counterparts is not just one context amongst others. This set of counterparts has a particular significance because it is the set that is normally relevant for first-person planning.

Thinking of cares as being central to identity in key contexts helps to make sense of some of the claims that are made by the advocates of identity-politics. If someone says that being gay, or being Deaf, is essential to their identity, I suggest that we cash this out as meaning that being gay (or being Deaf) is something that they care about a lot. When they plan, they thus 
only think of possible gay (or Deaf) people as being their counterparts. From such a perspective being gay (or being Deaf) is essential to who they are.

Thinking in terms of counterparts helps elucidate certain aspects of Frankfurt's account. Like counterparts, volitional necessities plausibly shift with context. In his work, Frankfurt uses the case of Luther as an example. Famously Luther found it impossible to betray his religious convictions - "Here I stand, I can do no other". Shoemaker points out that if the situation were slightly different, say a dearly loved daughter was threatened, then Luther would plausibly have viewed his options very differently (Shoemaker, 2003, p.107). Thinking in terms of counterpart theory can help us make sense of what is going on here. Our counterparts vary with context. In the situation in which Luther has no daughter then the possible people who are most like him in having the same cares (i.e. his relevant counterparts) do not betray his religious convictions. In the situation in which he has a daughter who he loves more than his religion, then his counterparts shift - now the possible people who are most like Luther are those who do not betray his daughter.

Using counterpart theory to make sense of Frankfurt's claims also explains why it is that some of his statements concerning the implications of betraying what we care about seem both to be, in a sense, profoundly true, and yet, also in another sense, clearly false. On Frankfurt's account a person is destroyed when they betray their cares. But exactly what this might mean needs to be treated very carefully. In his paper "Identification and Identity" (2002), Velleman stresses that it is a normal, although perhaps unfortunate, feature of human life that people can be fickle and that the things people care about very often do change. Frankfurt's account seems to imply that being fickle can be fatal, which is clearly false. 
Again, counterpart theory can help. The individuals that count as one's counterparts vary with the context in question. From the first-person point of view our counterparts are often those possible people who share our cares. The fact that we often think about modal contexts when we are making plans means that this choice of counterparts often makes sense. Against such a reference class it is true that an individual could not betray the people that he or she loves the individual has no counterparts that make the betrayal.

On the other hand, the context from which a third party views and judges an individual is different. When we judge another we generally do not know, or are not concerned about, their cares. We thus do not use the criteria of similarity of cares when we pick out the person's counterparts. Rather we use some other criteria - maybe bodily or psychological continuity. From our point of view the individual has counterparts in all those worlds in which there is someone like them who has a particular set of memories, or body. From such a context, we can say that as there are worlds that contain that person's counterparts in which they exist but have betrayed what they love.

At this point we can return to the scenarios with which I began this paper, and answer the questions of whether I might have been born prettier, or have been born a rhino. If we use counterpart theory neither of these questions has a straight answer. In different contexts we will pick out different possible entities as being my counterparts. In order to answer the question of whether I might have been prettier, we need to decide how we will pick out counterparts in the context in which we are speaking. Once we have done this, we can say that if some of my counterparts are prettier I might have been prettier. I suggest that, for the most 
part, it will make sense to think that I might have been more attractive. In most contexts, we will pick out my counterparts on the basis of similarity of cares, or of origins, or of memories, or of physical similarity, and I will have prettier counterparts. Turning to the rhino scenario, thinking of any context in which we would consider a rhino to be one of my counterparts is harder. Possibly, if my memories were implanted into an adult rhino, there are contexts in which we would consider that rhino to be my counterpart. In the scenario with which I began, however, my genetic material is transformed into rhino genetic material prior to my birth. I cannot think of any relevant similarity relations between the possible resultant rhinos and my human self that would lead us to judge the rhinos to be amongst my counterparts. Thus, we can say that I could not have been transformed into a rhino prior to my birth.

Some readers will find counterpart theory an unattractive option. At this point we should remember that in thinking about how an individual might have been we are forced to respond to Chisholm's Noah-Adam paradox, and to take a view on whether there are possible worlds in which two actual individuals have exchanged all their properties. As outlined at the beginning of this paper there are three options: 1 . claim that individuals have necessary properties (and use this to say that Noah and Adam cannot exchange properties), 2. embrace bare identities (and say that Noah and Adam can exchange properties), 3. embrace counterpart theory (and thus deny that talk of transworld identity strictly makes sense). I have argued that claiming that individuals possess necessary properties is problematic. Embracing counterpart theory or bare identities will both seem unattractive options to many, but with no other options in sight one must go for one or the other. In this section I have outlined what a counterpart theorist should say about the ways we might have been, in the next section I consider the stance of the believer in bare identities. 


\section{Bare Identities}

My discussion of the bare identity theorist will be brief as much of the discussion so far remains applicable. In How Things Might Have Been (2006), Penelope Mackie develops the view that individuals can have bare identities. Those who believe in bare identities hold that there is a possible world that differs from the actual world only in that two actual individuals have swapped all their properties (for example, Chisholm's world in which Noah and Adam have swapped all properties). Mackie admits that claiming that there can be bare identities is an unattractive option. The reason that Mackie embraces bare identities is that she thinks that claiming that individuals possess necessary properties that will prevent swaps is untenable, and that counterpart theory is an even less attractive option. Accepting that there are bare identities is thus the only route left open to her in responding to Chisholm's paradox.

Mackie thinks that there may be strictly speaking no limits to the alternative properties that an individual might possess. ${ }^{8}$ This does not follow directly from her claim that there are bare identities, as someone might believe in bare identities and also be, say a sortal essentialist (but Mackie also has doubts about sortal essentialism). If Mackie is right, and individuals might possess any properties at all, there will be possible worlds in which I am a rhino, or a

\footnotetext{
${ }^{8}$ Mackie limits her discussion to "normal individuals" such as "people, cats, trees and tables" (2006, p.vi). She doesn't say what counts as "an individual" but presumably "individuals" are defined such that I couldn't have been the set-theoretic union of Mondays and the back left leg of a cat.
} 
centipede. This being said, in most contexts, these far-out possibilities will not be worthy of consideration. Although there are worlds in which I am a rhino they will be far distant worlds.

Someone who accepts that there are strictly speaking no limits to the properties that I might possess can still hold that, as a matter of pragmatics, conversational context sets limits on the alternative possibilities that are worthy of consideration. If conversational context is used to set limits on the range of possible worlds that should be considered, then, if they wish, someone who thinks that individuals strictly speaking have no necessary properties will be able to talk loosely about "necessity", "identity" and "essences" in the same sort of way that the counterpart theorist does (indeed Mackie make some suggestions along these lines). For example, in certain contexts the counterpart theorist will take sameness of origin to be the property that is of importance for determining counterparts, and that in this context they will say that sameness of origin is "essential" (loosely speaking). Someone who believes that individuals have no necessary properties can engage in the same sort of loose talk if they take pragmatic constraints to set limits on the range of possible worlds that should be considered. Via this sort of manoeuvre, the claims made in Section 2 (on counterpart theory) on the special status of those possible worlds in which our cares are kept constant can be translated into terms that should be acceptable to someone who thinks that there are, strictly speaking, no limits to the properties that an individual might possess. 


\section{Conclusions}

In this paper I have sought to address the question of how I might have been. I started by considering the claims of those who think that a human's origins are necessary. There are various ways in which this idea might be made precise but I argued that all are problematic. If we abandon the idea that individuals possess necessary properties, then our only options in responding to Chisholm's Noah-Adam paradox is to either embrace counterpart theory or to hold that individuals can have bare identities. I did not attempt to arbitrate between these options, but instead explored what each type of theorist should say about how I might have been.

According to counterpart theory, individuals are strictly speaking worldbound. Counterfactual claims are made true by the facts concerning our counterparts - those possible people who are most similar to us in important respects. The "important respects" depend on the context in question. Counterpart theory allows us to talk of attributes that are "essential for our identity" in a loose sense - an attribute is essential for our identity if all our counterparts possess it.

Using Frankfurt's volitional account of identity I have suggested that one very important similarity relation that we use to pick out counterparts is similarity in respect to cares. Planning what to do is one of the main contexts in which we make use of modal reasoning in planning we compare possible courses of action. Given that we are unwilling to abandon the things we care about, when we plan, we only consider those courses of action that are compatible with our deepest cares. As such, from the position that we assume when we construct first-person plans, we have no counterparts who do not share our cares. Speaking 
loosely, we can say that our cares are essential for our identity. This helps make sense of Frankfurt's account, and also of claims that are made by the advocates of identity-politics who claim that, say, being gay can be essential to someone's identity. Using counterpart theory we can see that there is an important context in which such claims are true. However, at the same time, there are also other contexts, in which they are false - there are contexts in which we pick out counterparts on grounds other than their cares.

Finally, I argued that someone who believes in bare identities and thinks that individuals can have radically different properties in other possible worlds can consistently also hold that pragmatic constraints mean that in any particular conversational context only a limited range of possible worlds need to be considered relevant. Via using context to limit the range of worlds to be considered, the believer in bare identities can talk loosely about properties being "essential" or "necessary" in much the same sort of way as does the counterpart theorist. 


\section{References}

Appiah, A. (1990). "But would that still be me?" Notes on gender, "race", ethnicity, as sources of "identity". The Journal of Philosophy. 87: 493-499.

Chisholm, R., (1967). Identity through possible worlds: Some questions. Noûs, 1: 1-8.

Coburn, R. (1986). Individual essences and possible worlds. In M. Loux (ed.) The Possible and the Actual. Cornell University Press: Ithaca. Pp165-183.

Damnjanovic, N. (2010). No route to material origin essentialism? Erkenntnis. 72: 93-110.

De Grazia, D. (2005). Enhancement technologies and human identity. Journal of Medicine and Philosophy. 30: 261-283.

Dupré, J. (1993). The Disorder of Things. Harvard University Press: Cambridge MA.

Fara, M. and T. Williamson (2005) Counterparts and actuality. Mind, 114: 1-30.

Forbes, G. (1985). The Metaphysics of Modality. Oxford University Press: Oxford.

Frankfurt, H. (1971). Freedom of the will and the concept of a person. The Journal of Philosophy. 68: 5-20.

Frankfurt, H. (1999). Necessity, Volition and Love. Cambridge University Press: Cambridge. 
Frankfurt, H. (2004). The Reasons of Love. Princeton University Press: Princeton.

Glasgow, J. (2003) On the new biology of race. The Journal of Philosophy. 100: 456-474.

Griffiths, P. and R. Gray (1994). Developmental systems and evolutionary explanation. Journal of Philosophy. XCI: 277-304.

Hawthorne, J. and T. Gendler (2000). Origin essentialism: The arguments reconsidered. Mind. 109: 285-298.

Kahn, J. (1991). Genetic harm: Bitten by the body that keeps you? Bioethics. 5: 289-308.

Kripke, S. (1972, 1980) Naming and Necessity. Blackwell: Oxford.

Lewis, D. (1979). Counterpart theory and quantified modal logic. In M. Loux (ed.) The Possible and the Actual. Cornell University Press: Ithaca. Pp110-128 Originally in Journal of Philosophy (1968) 65: 113-126.

Lowe, E. J. (1998). The Possibility of Metaphysics: Substance, Identity and Time. Clarendon Press: Oxford.

Mackie, P. (2006a) How Things Might Have Been: Individuals, Kinds and Essential Properties. Clarendon Press: Oxford.

Mackie, P. (2006b) Transworld Identity. Entry in Stanford Encyclopedia of Philosophy. Available at http://seop.leeds.ac.uk/entries/identity-transworld/ 
Matthen, M. (2002). Origins are not essences in evolutionary systematics. Canadian Journal of Philosophy. 32: 167-182.

McKay, T. (1986). Against constitutional sufficiency principles. In M. Loux (ed) The Possible and the Actual. Cornell University Press: Ithaca. Pp295-304

Merricks, T. (2003). The end of counterpart theory. Journal of Philosophy. 100: 521-549.

Oderberg, D. (2007). Real Essentialism. Routledge: New York.

Parfit, D. (1984) Reasons and Persons. Clarendon Press: Oxford.

Pust, J (2004). Natural selection and the traits of individual organisms. Biology and Philosophy. 19: 765-779.

Robertson, T. (1998). Possibilities and the arguments for origin essentialism. Mind. 107: 729749.

Robertson, T. (2000). Essentialism: Origin and order. Mind 109: 299-307.

Robertson, T. and G. Forbes (2006). Does the new route reach its destination?. Mind. 115: 367-374.

Rohrbaugh, G. and L. deRosset (2004). A new route to the necessity of origin. Mind. 113: 705-725.

Salmon, N. (1981). Reference and Essence. Princeton University Press: Princeton. 
Salmon, N. (1986). Modal paradox: parts and counterparts, points and counterpoints. In P. French. T. Uehling, H. Wettstein. (eds.) Midwest Studies in Philosophy Vol XI. Studies in Essentialism. University of Minnesota Press: Minnesota. Pp 75-120

Sandel, M. (1982). Liberalism and the Limits of Justice. Cambridge University Press: Cambridge.

Shoemaker, D. (2003). Caring, identification, and agency. Ethics. 114: 88-118 .

Sober, E. (1995). Natural selection and distributive explanation. British Journal for the Philosophy of Science. 46: 384-7

Stalnaker, R. (1986). Counterparts and identity. In P. French. T. Uehling, H. Wettstein (eds.) Midwest Studies in Philosophy Vol XI. Studies in Essentialism. University of Minnesota Press: Minnesota. Pp121-140

Taylor, C. (1989). Sources of the Self: the Making of the Modern Identity. Harvard University Press: Cambridge, M.A.

Velleman, J. (2002) Identification and identity. In The Contours of Agency. S. Buss and L. Overton (eds.) MIT Press: Cambridge, M.A. Pp91-123

Wiggins. D. (2001) Sameness and Substance Renewed. Cambridge University Press: Cambridge. 
Zohar, N. (1991). Prospects for "genetic therapy" - Can a person benefit from being altered? Bioethics. 5: 275-288. 